\title{
Optimization of Ex-warehouse and Warehousing for Logistics Park Based on Computer Simulation
}

\author{
YANG Yan-mei ${ }^{1 a}$, LIU Xin-jun ${ }^{2 b}$ \\ Department of Computer Project, Tangshan Vocational College of Science and Technology, \\ Tangshan Hebei 063000, P.R.China
}

Keywords: Arena logistics park, ex-warehouse and warehousing, simulation research

\begin{abstract}
The logistics industry is regarded as a new product of the new time, and it is quickly covering most of the region. This paper is devoted to simulate the operation process of logistics park, the Arena modeling is used to construct the ex-warehouse and warehousing model of logistics park for its more in-depth analysis and research, so as to find out the optimization of logistics operation process, and improve the efficiency of resource utilization. The effective method of ex-warehouse and warehousing for logistics park is obtained, and it can provide some reference for high speed and effective logistics network.
\end{abstract}

\section{Introduction}

With the development of rapid pace of life and the development of the network shopping, the logistics industry has taken a great development and it is becoming more and more flourishing. The logistics park is responsible for the overall planning and coordination of the logistics process, so it is the most important link in the whole relationship network. It is different from the traditional goods circulation organization, the modern logistics park has more advantages, its advantages such as high utilization rate and high efficiency is not comparable to the traditional logistics. Warehousing is relatively important in the process of logistics park operation flow. In the current market competition intense environment, how to speed up the storage frequency, improve operational efficiency, reduce costs and optimize the inbound link is the only way for their enterprises to seek survival $^{[1]}$.

\section{Analysis of Logistics Park process}

Logistics park operation process is a huge system engineering, including the supply of information chain management, purchase, inspection, warehousing, warehousing, order receiving, order processing, order analysis ${ }^{[2,3]}$, delivery and inventory management, etc., the operation process of the logistics park is summarized as Figure 1, which is convenient for the readers to understand the main business operation process. 


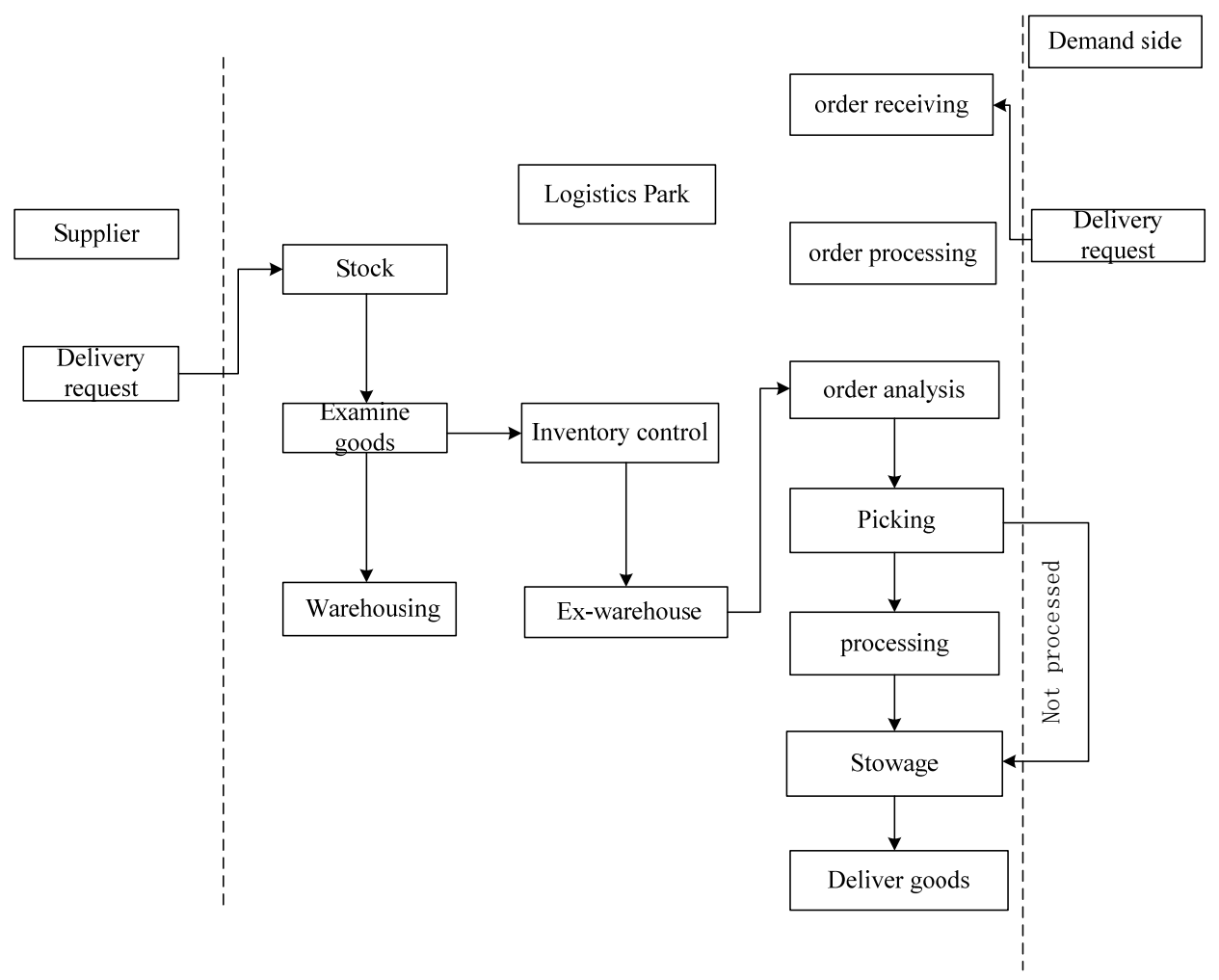

Fig.1 Operation process of the logistics park

\section{Case analysis}

\subsection{Storage details of Logistics Park}

(1) Structure analysis

A big logistics park is taken as an example, it has all contained functional areas in Figure 1, covers an area of 1591.16 million square meters. Assuming that the total logistics number is 69881.22 million tons, the whole process takes 2 days each time, it needs a total of 52319.11 square meters for piling up of goods. So this study can take the $4^{\text {th }}$ layers as an example, the use of each area needs reach 13079.75 square meters so as to meet the functional requirements. At the same time, it is strive to optimize the layout, and to obtain the most reasonable usage with minimum consumption. In order to describe the layout of the warehouse more intuitively ${ }^{[4,5]}$, the picture is taken as the form for expression of its network relations, it is shown in Figure 2.

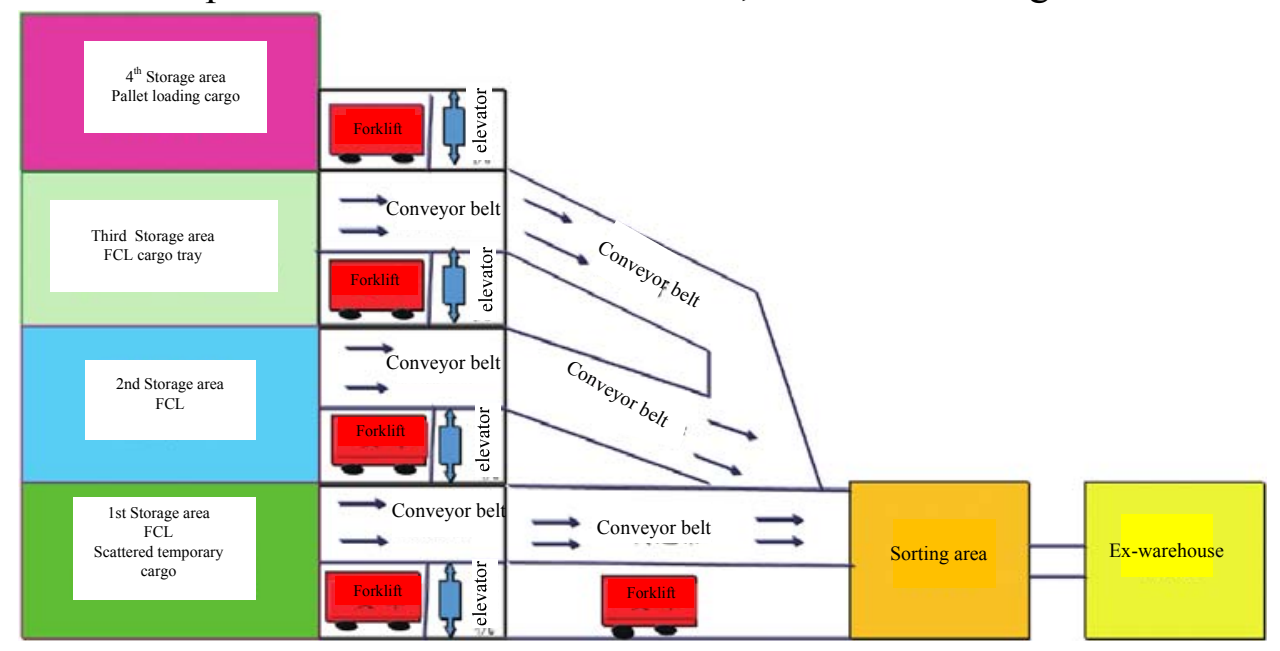

(2) Operation flow

Fig.2 Internal layout of the warehouse

In the 4 layers of the storage, the first layer is used as a sorting area, it is the distribution area of the entire circulation of goods, the second, third, and fourth layers can use the elevator to lift the 
delivery of goods to a layer. The second and third layers can transmit the goods through the conveyor, after the orderly sorting, then the next process can be carried out.

\subsection{Storage area analysis}

(1) In Table 1, the storage area personnel division is presented, through rational division of labor, it can ensure that the goods sorting, inventory, warehousing and ex-warehousing in an orderly manner.

Tab.1 intelligent configuration table of personnel distribution in center operating system

\begin{tabular}{|c|c|}
\hline Operation personnel & Main functions \\
\hline Stevedore & $\begin{array}{c}\text { Cargo handling, cargo handling and other specific } \\
\text { operation }\end{array}$ \\
\hline Picking operator & Goods sorting \\
\hline Office accountant & $\begin{array}{l}\text { Import and export management and statistics, } \\
\text { warehouse inventory, inspection, etc. }\end{array}$ \\
\hline
\end{tabular}

(2) Major facilities

The three major regional facilities such as the perfect logistics operation area, auxiliary area and ancillary facilities are the basic guarantee for the logistics operation, many operation processes such as cargo handling and storage are attached to these facilities.

(3) Distribution center equipments

As the core part of the whole logistics process, it is necessary to have efficient and effective facilities to ensure that the elevator and conveyor belts work and operation reliably and stably.

\subsection{Warehousing process}

Warehousing is relatively simple compared to the whole process, the flow network of warehousing process is described in Figure 3 clearly, a class of goods transport through the entire pallet, , another class of goods transport through FCL.

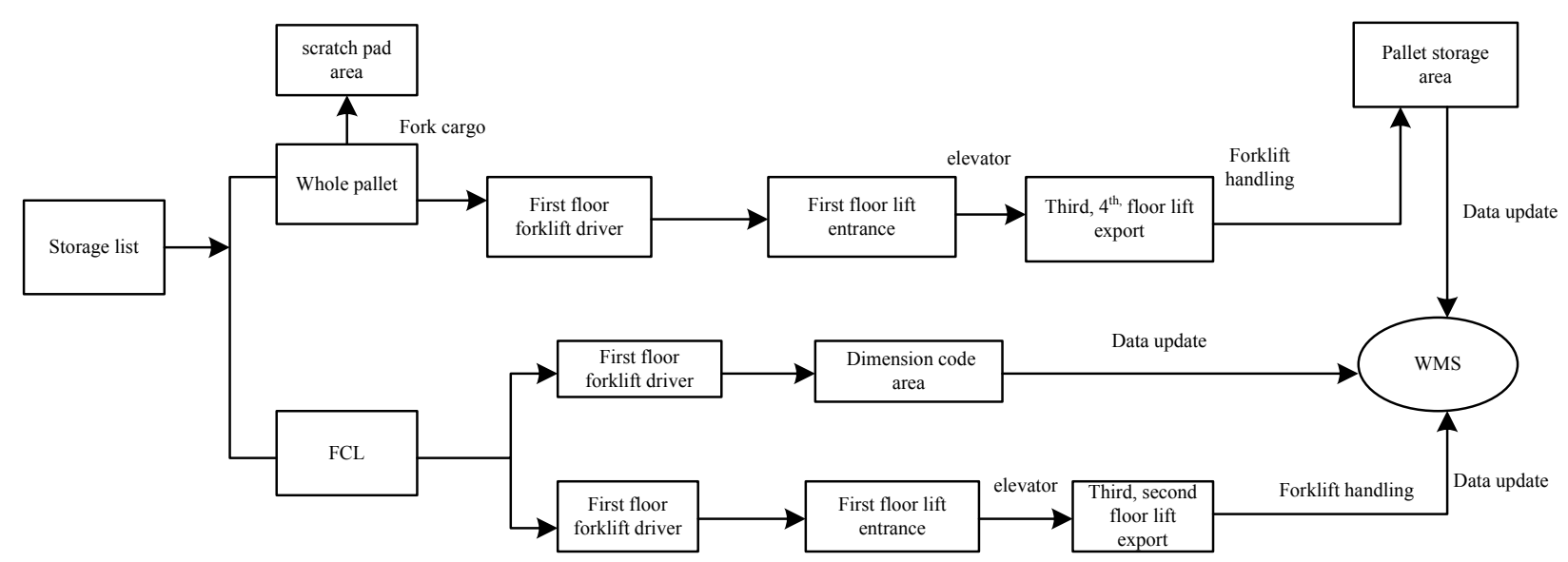

\subsection{Ex-warehousing operation process}

Fig. 3 Warehousing operation process

On the basis of the analysis of the warehousing process, the analysis of the ex-warehouse process is taken. First, the classification of goods before storage is obtained, the goods have two basic flows, through the overall distribution of the goods, a reasonable distribution and storage are realized, and finally it has to go through the link of information update of storage, so as to achieve the optimization of space utilization, but also a clear division of labor can be realized, and ensure the orderly and detailed inventory of the file. The ex-warehousing operation process is shown in Figure 4. 


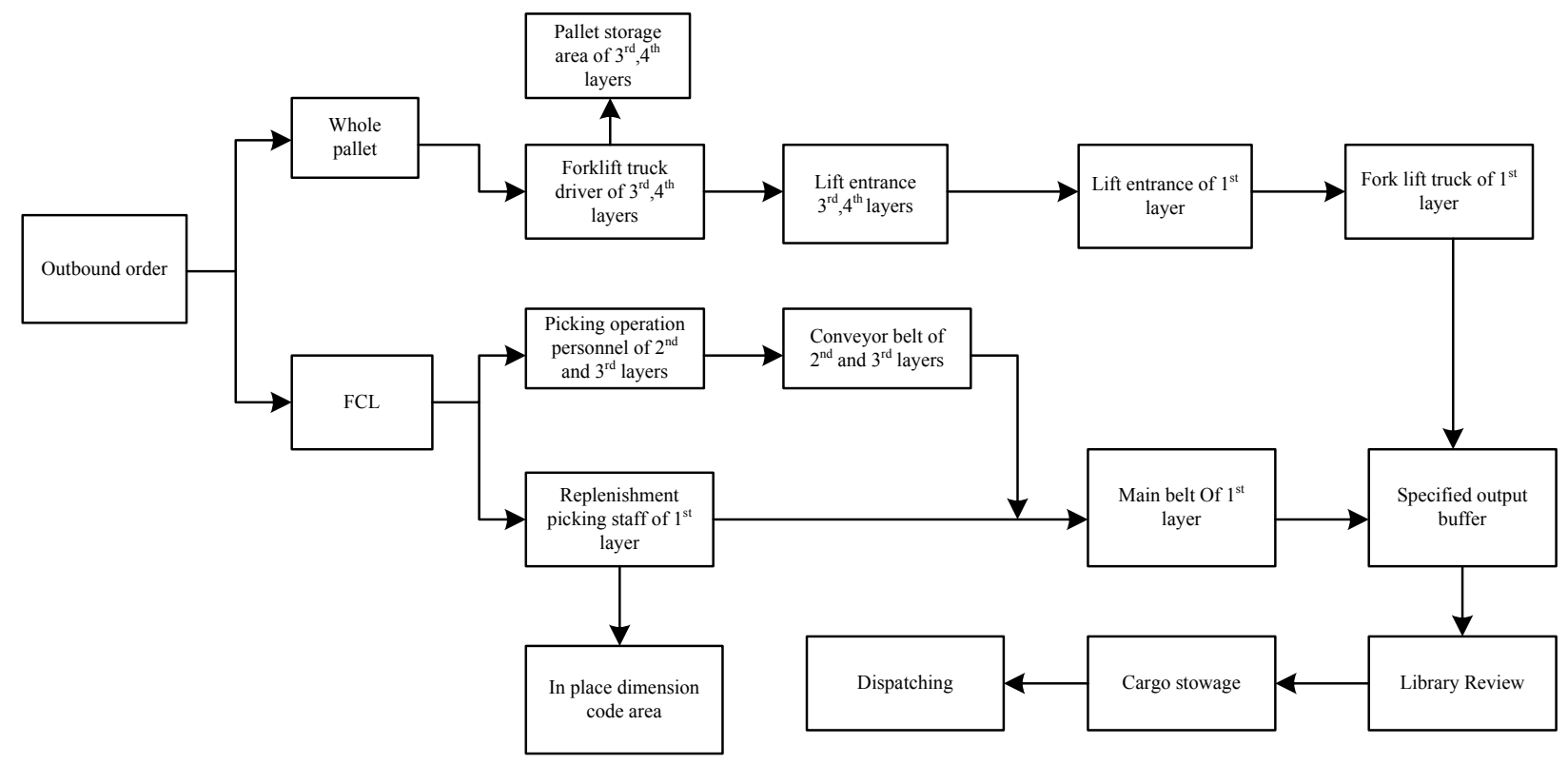

Fig.4 Ex-warehousing operation process

Figure 4 shows the operation process of the ex-warehousing operation in three ways, with respect to storage, library modes, and a scattered goods out of the library is described, for convenience of description, the library as a whole tray is defined as A, and FCL Library is defined as $\mathrm{B}$, and the scattered loose cargo is defined as $\mathrm{C}$.

For different goods using different ways of library, when the A class goods out of the library, the forklift drivers of 3rd or 4th layers will carry out the work of sorting goods according to the order processing and the command center, and then send to 1st layer through the lift, and the first layer of forklift driver is responsible for sending the goods to the inspection of personnel, through the inspection of the goods, the goods can be distributed. If it is not qualified, it will be returned for secondary treatment.

When the B class and $\mathrm{C}$ class goods out of the library, the order processing center schedule the related personnel of $1^{\text {st }}, 2^{\text {nd }}, 3^{\text {rd }}, 4^{\text {th }}$ layers for picking, similarly, it will go through the inspection of $1^{\text {st }}$ layer, to ensure that the distribution of goods to reach the distribution standard.

\section{Construction of ex-warehouse and warehousing system model}

\subsection{Modeling tool Arena}

Output Analyzer is analysis tool, users can obtain the data for further processing with Output Analyzer, it is attached to the powerful function of the computer, Arena can simulate various forms of integrated model simulation, it is better than the traditional analog method, which can avoid the problem as the traditional method is difficult to operate and other issues, so that it is more likely to be accepted by users, and it can take the analysis objectively.

\subsection{Modeling process}

Firstly, the whole process is assumed ideally, and the 30 days are taken as a cycle, working hours per day is defined as 16 hours, the speed of forklift is also set as $15 \mathrm{KM} / \mathrm{h}$ constantly, the following will take the definition of the actual operation.

First on the whole process of the assumption that the 30 days are taken as a cycle, the definition of working hours per day for 16 hours, the forklift is also a constant speed of $15 \mathrm{KM} / \mathrm{h}$. The following will be the definition of the actual operation.

1) Entity definition

Assume that storage in the FCL is A, whole tray goods is $\mathrm{B}$, and $\mathrm{A}, \mathrm{B}, \mathrm{C}$ are unchanged in a library, so through the simulation of the operating personnel in the actual process, the research is taken for the further analysis.

2) Resource integration 
First determine the various aspects of the staff, according to the assumed size of the project design, loading staff has 20 people, and corresponding to its proportion, it is equipped with 15 responsible picking aspects of personnel, 6 people if responsible for testing personnel. It can ensure that the entire process in the efficient operation of the case, the delivery of goods reach the inspection standards. In the following, the assumption of transport equipment is taken, as the most convenient and efficient cargo transport links, assuming that 6 sets of forklift trucks, with the loading and unloading tasks outside the transport work, the national standard is taken to simulate the speed of the forklift, 5 section conveyor belts are configured with speed as $16 \mathrm{~m} / \mathrm{min}$.

\subsection{Set up process model of ex-warehouse and warehousing}

This modeling process is also achieved through the Arena, in the simulation process of Arena multilayer, it has a huge advantage, the whole process can be more detailed analysis, is the Arena model is shown in Figure 5.

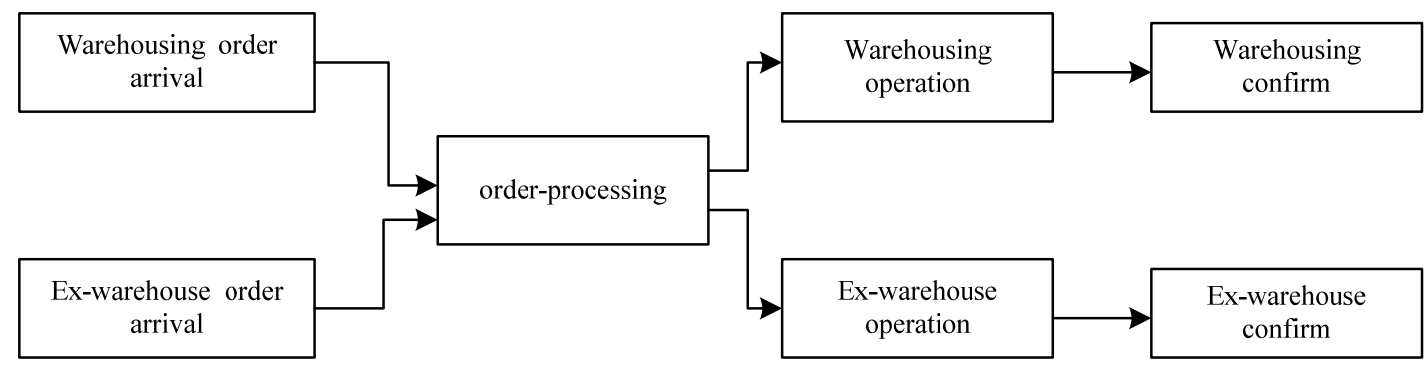

Fig.5 Structure diagram of Arena model

(1) Set up the operation model of warehousing operations

The warehousing operations model is shown in Figure 6.

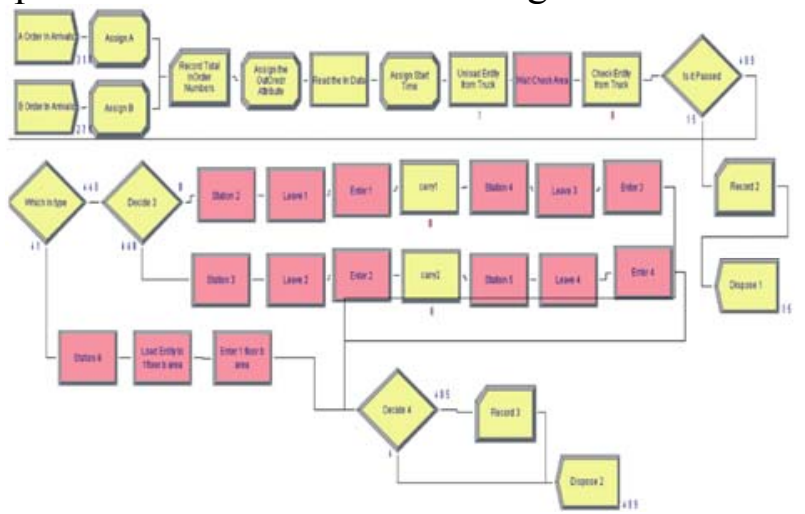

Fig.6 Warehousing operations model

Order processing center carries out the classification of goods for warehousing operations, and then through a series of modules to complete the whole process. The detailed explanation of the role of each module is described in following steps, the more complex the entire pallet storage operation is taken as example, 2 Create modules show goods waiting for storage, storage number is recorded with module statistics, in the information link for storage, it is realized by 3 Assign modules. Two modules of storage information are assigned value, a module assign value for storage time assignment, due to the number of goods is different, and the delivery mode is not the same. Through the 2 Write Read module to check, only after the inspection of the goods through the Decide module, it can be put in storage, otherwise the system will automatically return the goods. The Decide module analyzes the class of the goods to determine the distribution of the area, the $2^{\text {nd }}, 3^{\text {rd }}$ layers are two storage areas with station module to show, 2 Leave modules show the forklift. Process is taken as a module to achieve the elevator operation, the main responsibility is the docking with the forklift, the elevator will be assigned to the corresponding storage area, which is representative of the entire storage of the end of the operation. FCL storage operation can refer to the entire pallet storage.

(2) Set up the operation model of library operation

On the basis of modeling of storage operations, the ex-warehouse model is easy to work out, the 
ex-warehouse operation model is constructed, and it is shown in Figure 7.

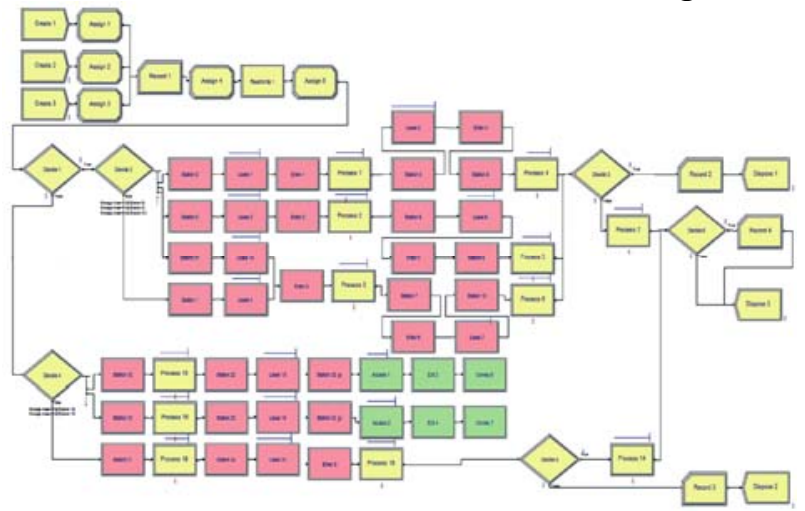

Fig.7 Ex-warehouse operation model

A Decid module is used for classification of different kinds of goods, conveyer belt is used to transport FCL and scattered cargo, lift is responsible for entire pallet cargo transport, and to allocate storage area according to the parameter setting and storage area by the station module. Sorting module is Process, through the simulation of the real operation of the time consumption of statistics, forklift is leave module, it is taken as a link between the transfer of goods, it will choose personnel placed in temporary storage area of goods adn send to the waiting area, staging area and waiting area are shown by the station module. Three modules such as access, exit and tous are used for realizing the function of conveyor belt transmission, cargo inspection personnel is responsible for warehouse inspection, in order to achieve the process module, and then Decide module takes qualified cargo pick out of the library, unqualified goods need to be transported to the processing area. After loading the whole simulation process is over.

\subsection{Data analysis}

Output results of resource utilization in delivery system are shown in Figure 8.

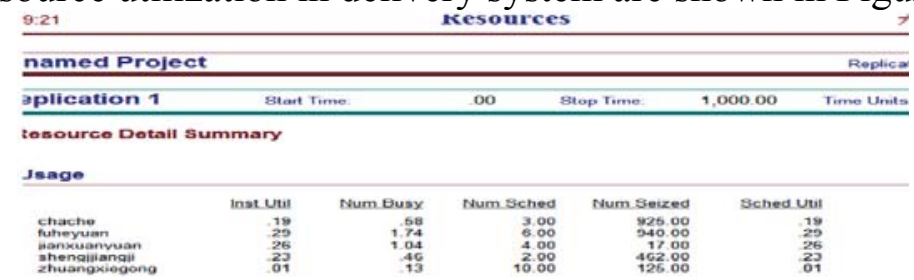

Fig. 8 Output results of resource utilization in delivery system

From the analysis results of Figure 8, we can see that the library is relatively weak in the whole process of the whole flow, it is true that the operation efficiency is low, the artificial utilization rate is low and the equipment is not complete, so we should grasp the key points to further optimize.

\subsection{Resource optimization}

Optquest is regarded as an excellent optimization analysis software, it can analyze the relevant data of the entire process, personnel and equipment is the control variable, the maximum order number of the library in the same time is the solution object, through the powerful analysis function of Optquest, optimize the allocation of personnel and equipment, the optimization process and results are shown in Figure 9. 


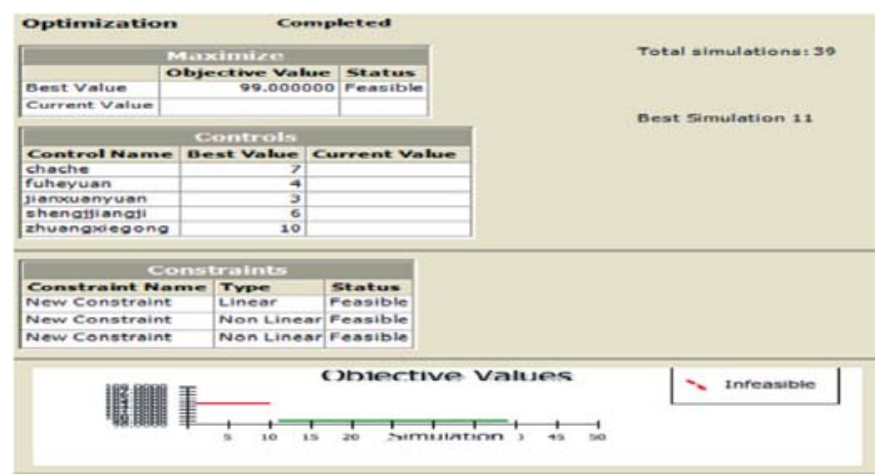

Fig.9 Optimization process and results

In the optimal solution it can be seen, after a reasonable ratio, the number of forklift is increased to 7 units, the review personnel are reduced from 6 to 4, while the sorting personnel are reduced to $1 / 5$, only 3 people, lifts are increased from 4 units to 6 units, the loading and unloading workers reduced by half, in the same conditions, the completion of the number of tasks is maximum, the best matching ratio is obtained.

\section{Conclusions}

The author makes use of Arena software to simulate the flow of the logistics park, according to the actual situation to determine the parameters, and a comprehensive analysis of the model is obtained. In the analysis results, the weak link of the whole process and the situation of idle resources are checked, and scientific optimization is obtained, so as to obtain the optimal proportion of personnel and equipment, this concept can provide a reference for the logistics industry to seek the optimal design of storage process.

\section{References}

[1] Zhao Jingying, Ma Changpu. Simulation and optimization of working time of B logistics company by Arena [J]. Research on science and technology management. 2011, (15).

[2] JIA An- chao,ZHOU Gang.Study on Selection of Suppliers Based on Rough Set and BP Neural Network[J]. Logistics Technology, 2012; 31(12): 229-232.

[3] GUO Qiu-xia,DENG Xiang-ming,OU Yang-jiang.Evaluation of Value Chain Risks Based on BP Artificial Neural Network[J].Logistics Technology.2011; 30(7): 120-122.

[4] Eldemerdash Y A, Dobre O A, and Liao B J. Blind identification of SM and Alamouti STBC-OFDM signals[J]. IEEE Transactions on Wireless Communications, 2015 14(2): 972-982.

[5] Karami E and Dobre O A. Identification of SM-OFDM and AL-OFDM signals based on their second-order cyclostationarity[J]. IEEE Transactions on Vehicular Technology, 2015, 64(3): 942-953. 